\title{
Força muscular expiratória e produção vocal na Doença de Parkinson
}

\author{
Daiane Fátima Biason \\ Fernanda Dal'Maso Camera \\ Miriam Salete Wilk Wisniewski
}

CADERNO DE RESUMOS

FisiSenectus. Unochapecó Ano 1 - Edição especial - 2013 p. 123

Daiane Fátima Biason, acadêmica do curso de Fisioterapia da URI - campus de Erechim, daybiason@hotmail.com

\section{Resumo}

Introdução: A Doença de Parkinson (DP) é uma patologia neurodegenerativa crônica, lentamente progressiva, caracterizada pela morte dos neurônios produtores de dopamina na parte compacta da substância negra. As manifestações clínicas ocorrem em todos os sistemas, incluindo o musculoesquelético, o respiratório e o estomatognático. A disartria hipocinética é a patologia da fala mais associada à DP, ocasionada por paralisia, fraqueza, tonicidade anormal ou incoordenação dos músculos usados na fala, coexistindo com alterações da respiração, fonação, ressonância, articulação e prosódia. Essas alterações levam a uma fala mal articulada, voz monótona e baixa (hipofonia) com características de rouquidão, aspereza e soprosidade. Objetivos: Verificar os benefícios de um programa de fortalecimento muscular expiratório sobre a fonação do indivíduo com diagnóstico de DP, estágio 2/3; mensurar a força muscular, o pico de fluxo expiratório, os volumes e capacidades pulmonares pré e pós-treinamento muscular expiratório; e correlacionar a pressão expiratória com a melhora da produção vocal. Metodologia: O estudo caracteriza-se como relato de caso, de caráter longitudinal, com abordagem quantitativa. A amostra será composta por um indivíduo (ambos os sexos) com diagnóstico de DP, em estágio 2/3, entre 50 e 70 anos, residente na cidade de Erechim, escolhido dentre os pacientes cadastrados na Clínica Escola de Fisioterapia da URI, não tabagista, sem doença pulmonar associada, sem acompanhamento fisioterapêutico e que consentir em participar através da assinatura do TCLE. O voluntário será submetido a avaliação da força muscular respiratória por meio da Manovacuometria, avaliação da relação $\mathrm{VEF}_{1} /$ CVF e CVF através da Espirometria, avaliação da eficácia da função pulmonar e a quantidade de ar expirado através do Pico de Fluxo Expiratório, avaliação da mobilidade tóracoabdominal por intermédio da Cirtometria e avaliação Fonológica por uma equipe de Fonoaudiologia da cidade. Após, a intervenção contará com 36 atendimentos de fisioterapia respiratória, 3 vezes por semana, 1 vez ao dia, utilizando-se para o treinamento, o aparelho muscular respiratório Threshold PEP®. 0 treinamento será realizado em 6 séries de 10 exercícios com intervalo de 1 minuto entre as séries. Concluindo-se os atendimentos, o voluntário será reavaliado por meio dos mesmos protocolos iniciais. Os dados serão analisados através de estatística descritiva e teste de Correlação de Spermann. Considerações finais: A articulação multiprofissional é a tônica deste estudo, no qual espera-se destacar os benefícios de um programa de fortalecimento muscular expiratório sobre a função fonatória e de comunicação de um indivíduo com Doença de Parkinson.

\section{Palavras-chave}

Modalidades de fisioterapia. Distúrbios da fala. Doença de Parkinson.

Monografia de Conclusão de Curso, do tipo relator de caso, em andamento. 